\title{
Pengembangan Video Program Event Smart Shopper Surprize Sebagai Media Promosi Tangcity Mall
}

\author{
Anita B. Wandanaya ${ }^{* 1}$, Dewi Immaniar Desrianti ${ }^{2}$, Piyan Sopyan ${ }^{3}$ \\ ${ }^{1,2,3}$ Program Studi Teknik Informatika Fakultas Sains dan Teknologi Universitas Raharja \\ E-mail: ${ }^{* 1}$ anita@ raharja.info, ${ }^{2}$ dewi.immaniar@ raharja.info, ${ }^{3}$ piyan.sopyan@ raharja.info
}

\begin{abstract}
Abstrak
Mengadakan sebuah program \& event adalah salah satu upaya yang dilakukan sebuah Mall dalam mempertahankan eksistensinya ditengah masyarakat. Begitupula yang dilakukan oleh Tangcity Mall, sebuah Golden Icon pusat perbelanjaan ekslusif yang berada di kawasan Kota Tangerang. Program event yang diselenggarakan adalah Smart Shopper Surprize yaitu program undian yang diadakan setiap enam bulan sekali. akan tetapi permasalahan yang dihadapi saat ini yaitu didalam penyebaran informasi dan promosi seputar event tersebut dirasa masih kurang, tejadi penurunan sekitar 15\% dari angka target 400 pendaftaran new member setiap bulannya. Dengan pengembangan video promosi ini diharapkan dapat meningkatkan jumlah customer loyal serta memberikan informasi terbaru kepada customer tentang program Smart Shopper Surprize yang sedang berjalan. Metode yang dilakukan yaitu: Pengumpulan Data, Analisa SWOT, Analisa Perancangan Media dan Konsep Produksi Media (KPM). Hasil yang didapat dari penelitian ini adalah video promosi event Smart Shopper Surprize yang dapat digunakan untuk meningkatkan angka pendaftaran new member dan meningkatkan traffic pengunjung setiap bulannya.
\end{abstract}

Kata Kunci-Mall, Event, Video Promosi

\begin{abstract}
Organizing a program \& event is one of the efforts made by a Mall in maintaining its existence in the community. The same is done by Tangcity Mall, an exclusive Golden Icon shopping center in the Tangerang City area. The event program being held is the Smart Shopper Surprize, which is a raffle program that is held every six months. However, the problems faced today, namely in the dissemination of information and promotion around the event, are still lacking. there is a decrease of about $15 \%$ from the target figure of 400 new member registrations per month. With the development of this promotional video, it is hoped that it can increase the number of loyal customers and provide the latest information to customers about the ongoing Smart Shopper Surprize program. The methods used are: Data Collection, SWOT Analysis, Media Design Analysis and Media Production Concept (KPM). The results obtained from this study are a promotional video for the Smart Shopper Surprize event which can be used to increase the number of new member registrations and increase visitor traffic each month.
\end{abstract}

Keywords—Mall, Event, Promotional Video 


\section{PENDAHULUAN}

Media Perkembangan Mall di kota tangerang yang cukup pesat menyebabkan masing masing mall harus mampu bersaing dan melakukan promosi dan publikasi atas produknya agar di kenal baik dan menghasilkan ketertarikan publik. Banyak cara yang di lakukan Building Management untuk mempromosikan dan mempublikasikan eksistensi mall, salah satunya dengan mengadakan program event.

Tangcity Mall merupakan salah satu pusat perbelanjaan terlengkap dan terbesar yang menjadikan kawasan central bisnis di Kota Tangerang menggunakan konsep superblock..

Tangcity Mall mempunyai Program Event Smart Shopper Surprize yaitu undian yang di adakan setiap enam bulan sekali. Berdasarkan hasil wawancara dengan stakeholder, bahwa permasalahan yang dihadapi saat ini yaitu di dalam penyebaran informasi dan promosi seputar event tersebut dirasa masih kurang, tejadi penurunan sekitar $15 \%$ dari angka target 400 pendaftaran new member setiap bulannya.

Menurut Noor (2009), Event adalah suatu kegiatan yang diselengarakan untuk memperingati hal-hal penting sepanjang hidup manusia, baik secara individu atau kelompok yang terkait secara adat, budaya, tradisi, dan agama yang diselenggarakan untuk tujuan tertentu serta melibatkan lingkungan masyarakat yang diseleng-garakan pada waktu tertentu. [1]

Menurut Maulani dkk(2016:212), Promosi adalah tindakan menginformasikan atau meningkatkan konsumen tentang spesifikasi produk atau merek. Promosi mempunyai kekuatan untuk menyampaikan pesan, dan diperlukan perancangan khusus agar promosi tersebut memiliki visual yang kuat dan menciptakan keserasian di dalam rangkaian pemasaran, karena promosi adalah berkaitan langsung dalam upaya untuk memperkenalkan produk kepada konsumen dengan memikat hati mereka melalui pemberian kesan - kesan baik, yang mampu diingat dan dirasakan oleh konsumen.[2]

Penelitian ini bermaksud untuk mengembangkan promosi yang sedang berjalan di Tangcity Mall, dengan pengembangan video promosi ini diharapkan dapat meningkatkan jumlah customer loyal serta membantu divisi Promotion and Events \& Tenant Relations dalam memberikan informasi terbaru kepada customer tentang program Smart Shopper Surprize yang sedang berjalan.

\subsection{Literature Review}

Dalam penelitian ini, penulis melakukan literature riview terhadap penelitian-penelitian sebelumnya, sebagai berikut :

1. Penelitian yang dilakukan oleh Handayani, dkk (2019)"Video Company Profile Live Kota Tangerang dengan Teknik editing menggunakanAdobe Premiere Pro". Tujuan dari penelitian ini adalah memperkenalkan program pemerintah Kota Tangerang, kemudian diupload dalam sosial media youtube dengan tujuan dapat dilihat oleh masyarakat luas, khususnya warga Kota Tangerang.Hasil Penelitian berupa video profile program Kota Tangerang Live dibuat dalam format mp4.[3]

2. Penelitian yang dilakukan olehIsmayani, Diah (2018)"Perancangan Video Iklan Promosi Profil Wisata Puncak Bila Riase' Kabupaten Sidrap. Penelitian ini membahas tentang Video Promosi PariwisataPuncak Bila Riase' Kabupaten Sidrap. Tujuan dari penelitian ini adalah memberikan tambahan wawasan bagi Dinas Kebudayaan dan Pariwisata Kabupaten Sidrap tentang pentingnya Desain Komunikasi Visual yang memberikan informasi tentang media yang efektif dan efisien melalui konsep perancangan video profil untuk mengenalkan objek wisata yang berada di Kabupaten Sidrap kepada masyarakat luas.[4]

3. Penelitian yang dilakukan oleh Prasetyo, Dwi dan Denny Indrayana Setyadi (2017)"Perancangan Film Pendek Bertema Wisatadengan Pendekatan Storytelling sebagai MediaPromosi Pulau Bawean. Penelitian ini membahas tentang Video Promosi PariwisataPulau Bawean. Tujuan dari penelitian ini adalah memberikan image positif 
tentang keindahan pulau Bawean dan dalam pengembangannya dapat ditambahkan objek-objek wisata lain yang dapat dijadikan konten dalam sebuah film.[5]

4. Penelitian yang dilakukan oleh Putra dan Vella Carisa (2019)[53] "Video Kabupaten Tangerang Pada Dinas Disporabudpar Pariwisata. Penelitian ini membahas tentang Promosi wisata Kabupaten Tangerang. Tujuan dari penelitian ini adalahUntuk mencapai target Disporabudpar dalam hal menyampaikan informasi tentang objek wisata Kabupaten Tangerang kepada masyarakat dan wisatawan, serta meningkatkan jumlah kunjungan wisatawan.[6]

5. Penelitian yang dilakukan oleh Yang Lai Fong dkk (2017), "The Impact of Tourism Advertisement Promotional Videos on Young Adults". Penelitian ini membahas tentang bagaimana orang dewasa muda mengambil keputusan pada video promosi wisata. Tujuan dari penelitian ini adalah Untuk memahami bagaimana video promosi iklan pariwisata mempengaruhi pengambilan keputusan orang dewasa muda.[7]

\section{METODE PENELITIAN}

Dalam meningkatkan penelitian ini, maka terdapat beberapa metode yang digunakan dalam proses pengumpulan data, yang diperlukan dalam Pengembangan Video Program Event Smart Shopper Surprize:

1. Metode Analisis Permasalahan, menganalisis permasalahan yang terdapat pada Tangcity Mall

2. Metode Pengumpulan Data, pengumpulan data dengan beberapa cara, seperti berikut :

1) Observasi (Pengamatan), metode pengumpulan data dengan cara mengamati atau meninjau langsung ke Tangcity Mall

2) Interview (Wawancara), metode ini digunakan dengan datang secara langsung dan mengajukan beberapa pertanyaan dan jawaban kepada stakeholderTangcity Mall

3) Studi Pustaka yaitu mempelajari buku-buku yang diperlukan untuk digunakan dalam penelitian ini.

3. Metode Konsep Produksi Media (KPM).Tahapan Konsep Produksi Media (KPM) adalah tahapan yang dikerjakan untuk menyusun proses produksi media agar terkonsep dengan lebih jelas, baik dan sistematis agar menghasilkan produksi media sesuai dengan keinginan dari stakeholder. Proses ini melalui berbagai tahapan seperti berikut : (1) Pre Production, (2) Production, (3) Postproduction.

\section{HASIL DAN PEMBAHASAN}

Pengembangan video program Smart Shopper Surprize ini menggunakan metode Konsep Produksi Media (KPM). Konsep Produksi Media dibagi menjadi tiga bagian seperti yang dijelaskan Sunarya, dkk (2017:108-111).[8]

\section{KPM}

\section{PREPRODUCTION}

\section{PRODUCTION}

\section{POSTPRODUCTION}

Gambar 1. Bagan Konsep Produksi Mavib (KPM) 


\subsection{Preproduction}

Pre Production adalah step atau langkah awal dimulainya suatu karya diantaranya ide, perencanaan, dan persiapan dari Konsep Produksi Media [8].

\subsubsection{Ide atau Gagasan}

Media informasi merupakan realisasi dari sebuah ide pemikiran atau gagasan yang telah kita masukkan kedalam video [8]. Sebuah ide atau gagasan yang telah tercipta kemudian dikembangkan lagi dengan mengumpulkan data-data berdasarkan masalah yang ada. Kemudian dalam penelitian ini konsep yang dibutuhkan dalam pengembangan video Smart Shopper Surprize pada Tangcity Mall ini menampilkan informasi tentang panduan Smart Shopper Card dan keuntungan-keuntungn dari mengikuti program tersebut dengan konsep yang menarik dengan penambahan effect visual dan juga music agar dapat meningkatkan minat pelanggan untuk berbelanja.

\subsection{2. $\quad$ Sinopsis}

Menurut Fatoni dan Nofi Puspitasari (2016:58) menjelaskan "Sinopsis adalah ringkasan sebuah cerita yang diperlukan untuk memberikan gambaran secara ringkas dan padat tentang tema atau pokok cerita secara keseluruhan".[9].

Berikut adalah sinopsis dari video Smart ShopperSurprize :

"Seorang pengunjung memasuki Lobby lalu memasuki sebuah Toko Fashion dan berbelanja, setelah berbelanja pengunjung tersebut menuju ke Redemption Counter untuk mendaftarkan diri sebagai anggota Smart Shopper, dijelaskan keuntungan dari mengikuti program event tersebut salah satunya adalah dapat mengikuti pengundian grandprize 1 unit mobil all new Nissan Livina"

\subsubsection{Narasi}

Narasi adalah tulisan yang menyimpan berbagai pikiran, ide dan gagasan yang dikemas dengan konsep yang menarik lalu akan ditampilkan menjadi sebuah naskah akhir lalu akan ditampilkan visualisasinya. Berikut ini adalah naskah pada video program event Smart Shopper Surprize :

"Smart Shopper Surprize 26 September 2020 - 26 Maret 2021, menangkan hadiah all new Nissan livina \& Samsung Galaxy S20+ dengan Telkomsel Poin, 1 all new Nissan Livina, 3 Honda Beat, 4 Samsung Galaxy S20+, 5 Voucher Electronic City@5 Juta. 5 Fine Gold @5gram, Gratis! Dengan minimal belanja 100 ribu, Point Prizes 22 Juni 2020 - 26 Maret 2021, Kumpulkan poinnya tukarkan dengan hadiah langsung, Gratis! Voucher belanja TaangcityMall @2 juta setiap bulan bagi top spender, Supprorted by Telkomsel, be a smart shopper!"

\subsubsection{Storyboard}

Menurut Sunarya dkk (2016:321)“Storyboard adalah rangkaian gambar ilustrasi yang berusaha menjelaskan bahasa tulisan scenario kedalam bahasa visual”.[10]

Berikut ini Storyboard yang digambarkan per-scene, berdasarkan alur cerita yang dirancang pada video Smart Shopper Surprize : 


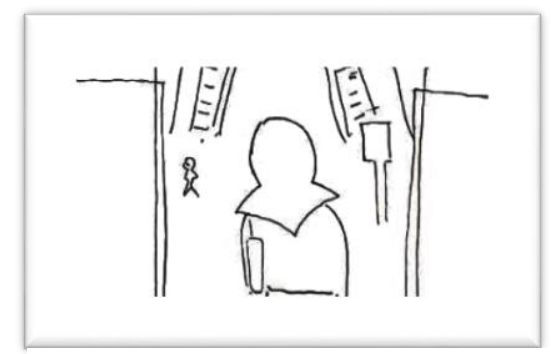

Gambar 2. INT/ Scene 6 / Night / Medium Shot/Menampilkan video pengunjung memasuki Lobby

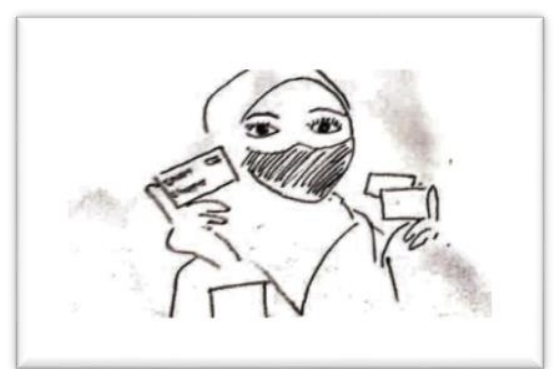

Gambar 4. INT/ Scene 15/ Night/

Medium Shot/Menampilkan pengunjung dengan 2 buah kartu Smart Shopper

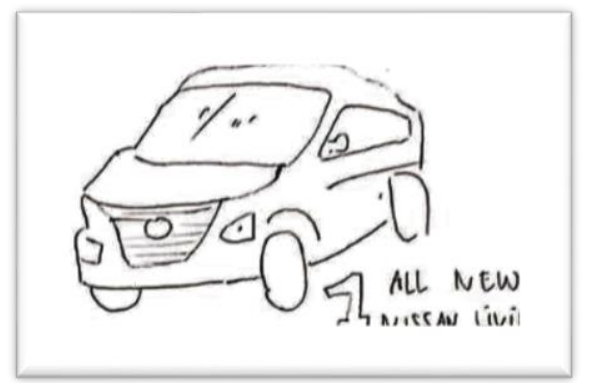

Gambar 6. / Scene

18/Menampilkan video hadiah pengundian

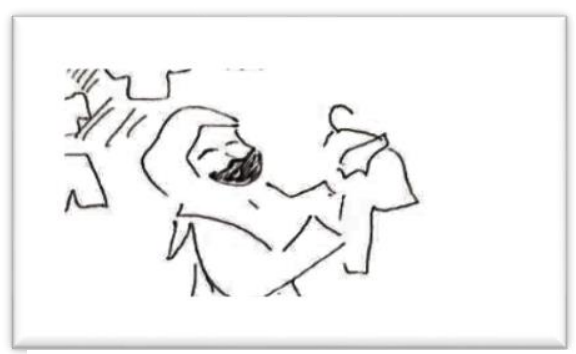

Gambar 3. INT/ Scene 10/ Night/

Medium Shot/Menampilkan video pengunjung memilih product

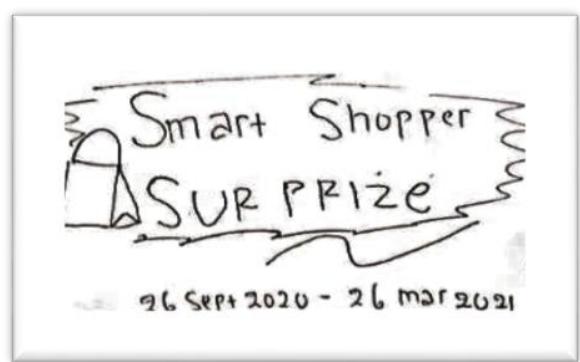

Gambar 5. / Scene 16/

Menampilkan video Smart

Shopper Surprize \& periode

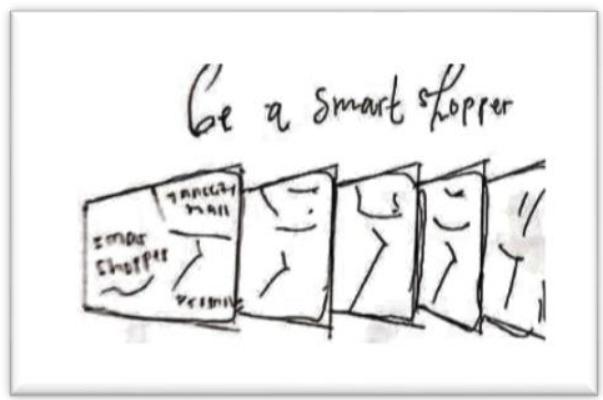

Gambar 7. / Scene 21/

Menampilkan video berbagai jenis kartu smart shopper

\subsubsection{Script Writing}

Script writing dalam video Smart Shopper Surprize ini adalah gambaran alur cerita dari video tersebut yang terdiri dari visual dan audio, yang ada pada tabel 1 dibawah ini.

Tabel 1. Sricpt Writing

\begin{tabular}{|r|l|l|}
\hline No. & Visual & Audio \\
\hline 1. & $\begin{array}{l}\text { Menampilkan video seorang } \\
\text { pengunjung memasuki Lobby }\end{array}$ & Music Tropical Saxophone \\
\hline 2. & $\begin{array}{l}\text { Menampilkan video pengunjung } \\
\text { memilih product }\end{array}$ & Music Tropical Saxophone \\
\hline 3. & $\begin{array}{l}\text { Menampilkan video pengunjung } \\
\text { dengan 2 buah kartu Smart Shopper }\end{array}$ & Music Tropical Saxophone \\
\hline 4. & Menampilkan videoSmart Shopper & Music Tropical Saxophone \\
\hline
\end{tabular}




\begin{tabular}{|r|l|l|}
\hline & Surprize\& periode & \\
\hline 5. & $\begin{array}{l}\text { Menampilkan video hadiah } \\
\text { pengundian }\end{array}$ & Music Tropical Saxophone \\
\hline 6. & $\begin{array}{l}\text { Menampilkan video berbagai jenis } \\
\text { kartu smart shopper }\end{array}$ & Music Tropical Saxophone \\
\hline
\end{tabular}

\subsubsection{Rundown}

Menurut Tama dkk (2018:103), Rundown merupakan susunan cerita yang dirancang oleh durasi waktu. [11]

Tabel 2. Rundown

\begin{tabular}{|l|l|l|l|l|l|}
\hline No. & Scene & Location & Duration & INT/EXT & Description \\
\hline 1. & 1. & $\begin{array}{l}\text { Tangcity } \\
\text { Mall Indoor } \\
\text { Lobby } \\
\text { Sudirman }\end{array}$ & $\begin{array}{l}\text { 00:00:11:15- } \\
00: 00: 13: 08\end{array}$ & INT & $\begin{array}{l}\text { Menampilkan } \\
\text { video seorang } \\
\text { pengunjung } \\
\text { memasuki Lobby }\end{array}$ \\
\hline 2. & 2. & $\begin{array}{l}\text { Tangcity } \\
\text { Mall Indoor } \\
\text { Toko } \\
\text { Giordano }\end{array}$ & $\begin{array}{l}00: 00: 25: 15- \\
00: 00: 29: 20\end{array}$ & INT & $\begin{array}{l}\text { Menampilkan } \\
\text { video pengunjung } \\
\text { memilih product }\end{array}$ \\
\hline 3. & 3. & $\begin{array}{l}\text { Tangcity } \\
\text { Mall Indoor } \\
\text { Ground } \\
\text { Floor }\end{array}$ & $\begin{array}{l}00: 00: 47: 04- \\
00: 00: 50: 00\end{array}$ & INT & $\begin{array}{l}\text { Menampilkan } \\
\text { video pengunjung } \\
\text { dengan 2 buah } \\
\text { kartu Smart } \\
\text { Shopper }\end{array}$ \\
\hline
\end{tabular}

\subsubsection{Analisa Perancangan Media}

Dalam peningkatan Video Smart Shopper Surprize ini, menggunakan software komputer grafis yaitu : Adobe Premiere Pro CS6 dan Adobe After Effect Pro Cs6

\subsection{Production}

Production adalah tahap selanjutnya dalam konsep produksi media. Dalam proses produksi, kerjasama antara talent dan crew sangat dibutuhkan. Bahkan setiap crew dari masing - masing jobdesk harus menjalin kerjasama yang solid [8]. Dalam pengembangan video event Smart Shopper Surprize ini, ide atau gagasan yang telah dibuat sebelumya dimasukkan kedalam proses shooting dan perlu persiapan pada tahap produksi yang harus diperhatikan dengan baik seperti semua unsur teknis, naskah, pemain, dan sinematografi yang dijalankan sesuai dengan arahan Sutradara. Dalam menjalankan tahapan production, memerlukan tahapan perencanaan multimedia, perencanaan audio visual, dan perencanaan broadcasting.

\subsubsection{Strategi Multimedia}

Strategi multimedia diperlukan untuk penyampaian video, teks dan musik dengan menampilkan visualisasi berbentuk audio visual, dilengkapi juga dengan berbagai visual effect dan backsound yang bertujuan untuk membantu pihak Tangcity Mall dalam mempromosikan event yang sedang berjalan yaitu Smart Shopper Surprize meningkatkan pendaftaran member baru pada program Smart ShopperSurprizeperiode ini, mempertahankan customer loyal, dan meningkatkan traffic pengunjung setiap bulannya. Dalam pengembangan video Event Smart 
Shopper Surprize ini, media sosial yang digunakan yaitu Instagram Tangcity Mall dan You Tube dari Tangcity Mall itu sendiri.

\subsubsection{Market Segmentation}

1. Khusus : Kota Tangerang

2. Umum : Wilayah Banten \& Nasional
a. Jenis Kelamin : Pria dan Wanita
b. Kelas Ekonomi : Menengah
c. Usia : 18 tahun keatas
d. Sasaran : 1 . Masyarakat Kota Tangerang
2. Pengunjung Tangcity Mall
3. Penghuni Novotel \& Apartment Skandinavia

3. Psikografi : Masyarakat Kota Tangerang Selatan, Pengunjung Tangcity Mall, dan Penghuni Hotel \& Apartment di kawasan Tangcity Mall yang ingin mengetahui informasi dan promosi lebih lanjut tentang pogram EventSmart Shopper Surprize.

\subsubsection{Program Multimedia}

Program multimedia yang digunakan dalam pengembangan media Video Event Smart Shopper Surprize dengan menggunakan software penunjang yaitu Adobe Premiere Pro CS6 dan Adobe After Effect Cs6 Terdapat tiga tahapan program multimedia dari media video promosi yang dirancang, yaitu : (1) Teks dalam video Event Smart Shopper Surprize ini, teks yang digunakan pada bagian low third \& hadiah pengundian menggunakan Font Tahoma, MS UI Gothic dan Myriad Pro. (2) Gambar yang digunakan di video Event Smart Shopper Surprize ini adalah gambar berbagai macam hadiah undian diantaranya sebuah mobil, motor, dan smartphone dalam bentuk png, lalu logo dari Tangcity Mall, logo berbagai sponsor dan logo dari Universitas Raharja kemudian digabungkan dengan video yang berformat mp4. (3) Sound yang digunakan di Video Event Smart Shopper Surprize ini adalah backsound yang berjudul Tropical Saxophone.

\subsubsection{Strategi Audio}

Strategi audio yang digunakan dalam pengembangan video event Smart Shopper Surprize ini, dibuat dengan menggunakan jenis musik upbeat Saxophone. Pemilihan jenis musik tersebut untuk menciptakan suasana audio yang tidak membosankan, bersemangat dan juga memberi kesan yang positif.

\subsubsection{Program Audio}

Program audio dalam video promosi ini sangatlah penting guna mengontrol suara agar sesuai serta seimbang dengan visualnya, adapun suara yang ingin ditampilkan berupa instrumen music saxophone yang upbeat dengan format .mp3 yang berjudul Tropical Saxophone.

\subsubsection{Tujuan Visual}

Tujuan visual pengembangan video event Smart Shopper Surprize dibuat dengan semenarik mungkin agar masyarakat maupun pengunjung tertarik dengan event Smart Shopper Surprize setelah menonton video ini. Dengan visual effect yang ditampilkan simple, jelas, informatif serta menarik tentunya disesuaikan dengan konsep dan keinginan dari pihak Tangcity Mall. 
Tabel 3. Kesan Visual Effect

\begin{tabular}{|l|l|}
\hline Visual Effect & Kesan yang ditimbulkan \\
\hline Opening & Simple, Natural \\
\hline Animasi hadiah undian & Simple, Interaktif, Ceria \\
\hline Outro Bumper & Simple, Interaktif \\
\hline
\end{tabular}

\subsubsection{Strategi Visual}

Strategi visual adalah strategi dalam pembuatan video untuk memberikan sentuhan visual effect pada video yang dirancang agar terlihat lebih menarik, mudah dipahami, lebih kreatif dan terlihat lebih nyata. Tampilan Visual effect yang digunakan dalam perancangan video promosi ini, menampilkan beberapa unsur seperti : video program event yang dibuat menggunakan software adobe after effect. Dimana software tersebut dapat menampilkan animasi yang lebih beragam.

\subsubsection{Perencanaaan Broadcasting}

Perencanaan Broadcasting adalah tahapan akhir dari proses production. Dalam perencanaan broadcasting dibutuhkan promosi menarik dan kreatif yang memiliki tujuan untuk menjangkau sasaran yang lebih luas dengan penyebaran yang efektif serta efisien sehingga perencanaan broadcasting sangat perlu dilakukan. Perencanaan broadcasting memiliki tujuan untuk dapat menarik minat pelanggan terhadap event Smart Shopper Surprize.

\subsubsection{Tujuan Broadcasting}

Tujuan broadcasting adalah tujuan untuk menjangkau jumlah penonton secara luas dan untuk memberikan informasi serta mempromosikan apa saja keuntungan dengan mengikuti program event Smart Shopper Surprize.

\subsubsection{Strategi Broadcasting}

Strategi Broadcasting sangatlah dibutuhkan untuk mempromosikan pengembangan video event Smart Shopper Surprize, agar dapat meningkatkan pendaftaran member baru dan customer loyal. Video promosi ini akan diimplementasikan dan ditampilkan pada Youtube "Tangcity Mall" serta media sosial Instagram "Tangcity Mall" dan juga akan ditayangkan dalam sebuah TVC yang berada di Redemption Counter.

\subsubsection{Program Broadcasting}

Program broadcasting dalam pengembangan video event Smart Shopper Surprize ini disampaikan melalui media : (1) Media video profile ini akan di upload melalui Youtube channel milik Tangcity Mall yang bernama "Tangcity Mall" dengan judul video "Smart Shopper Surprize", yang bertujuan untuk menyebarluaskan dan mempermudah masyarakat maupun para calon member untuk menonton video promosi ini secara lengkap, dan mudah diakses oleh siapa saja yang memiliki jaringan internet. (2) Sesuai dengan segmentasi pasar Tangcity Mall di zaman modern ini, hampir semua masyarakat memiliki akun instagram. Hal ini sangat efektif untuk mengimplementasikan video program Event Smart Shopper Surprize yang dipublish ke akun instagram milik Tangcity Mall. 


\subsection{Post Production}

Menurut Sunarya dkk (2016:321),Post Production adalah proses finishing atau proses akhir dari sebuah karya sampai menjadi sebuah video yang utuh dan mampu menyampaikan isi atau pesan kepada audience. Dalam proses post production semua gambar yang didapat pada proses production dikumpulkan di edit oleh seorang editor. Kegiatan pemasaran dan distribusi juga masuk di dalam proses post production.[8]

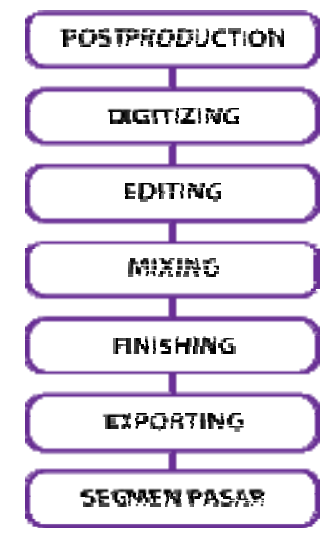

Gambar 8. Tahap Postproduction

\subsubsection{Tampilan Isi}

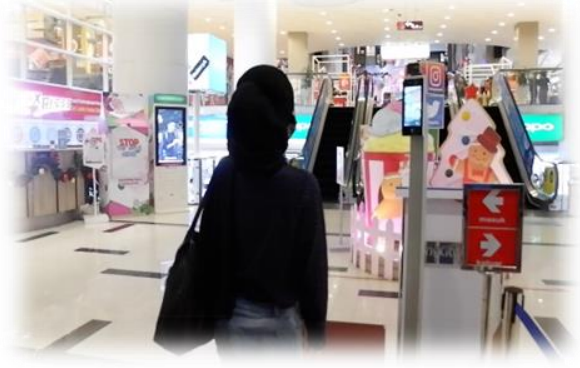

Gambar 9. INT/ Scene 6 / Night / Medium Shot/Menampilkan video pengunjung memasuki Lobby

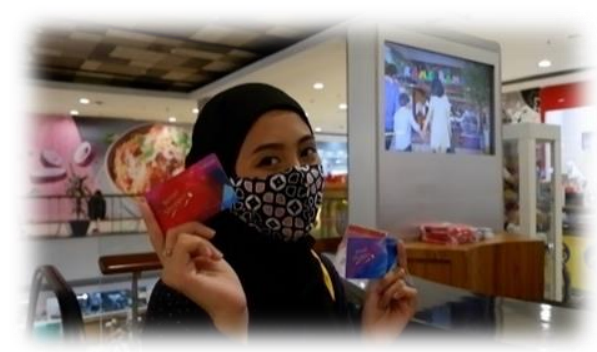

Gambar 11. INT/ Scene 15/ Night/ Medium Shot/Menampilkan pengunjung dengan 2 buah kartu Smart Shopper

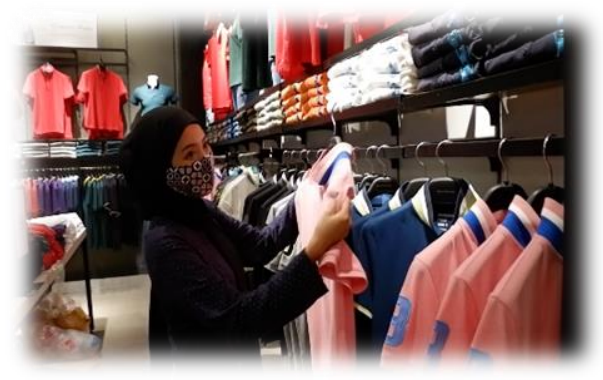

Gambar 10. INT/ Scene 10/ Night/ Medium Shot/Menampilkan video pengunjung memilih product

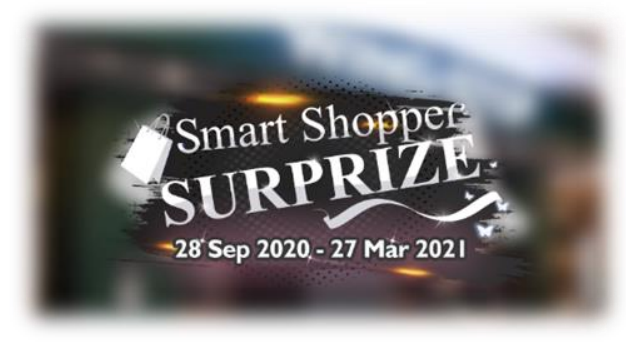

Gambar 12. / Scene 16/ Menampilkan video Smart Shopper Surprize \& periode 


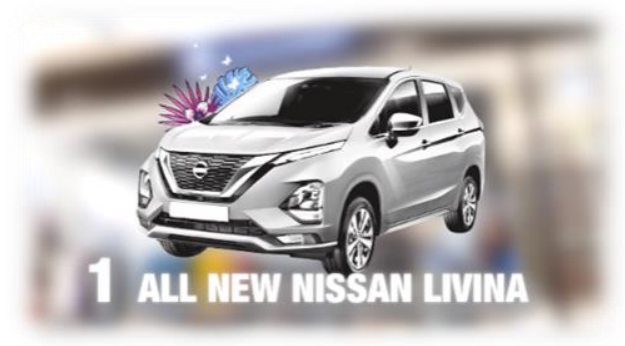

Gambar 13. / Scene 18/Menampilkan video hadiah pengundian

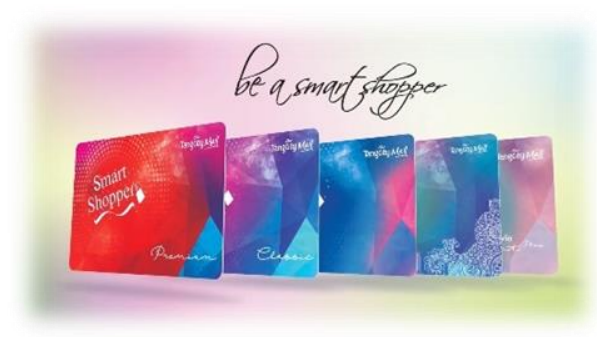

Gambar 14. / Scene 21/ Menampilkan video berbagai jenis kartu smart shopper

\section{KESIMPULAN}

1. Dalam membuat konsep media video promosi yang menarik dan dapat memenuhi kebutuhan informasi dan promosi event Smart Shopper Surprize pada Tangcity Mall yaitu dengan konsep video yang kreatif dan informatif yang terdapat audio menggunakan musik, tampilan visual berkualitas HD dan dilengkapi dengan berbagai visual effect, sehingga dapat menjadi daya tarik bagi masyarakat atau pelanggan yang melihatnya.

2. Informasi yang akan disampaikan melalui pengembangan media video Smart Shopper Surprize ini yaitu meliputi: Smart Shopper Card, Smart Shopper Privilege, dan Smart Shopper Guide sehingga pelanggan dapat dengan mudah memperoleh informasi terbaru seputar penawaran-penawaran/ diskon-diskon khusus yang diberikan para tenant atau partner yang berpartisipasi dalam program Smart Shopper Card, yang dapat dinikmati oleh para pemegang Smart Shopper Card.

3. Pengembangan Video Program Event Smart Shopper Surprize ini bertujuan agar Tangcity Mall dapat mencapai target pendaftaran new member di angka 400 orang perbulan pada program EventSmart Shopper periode ini, mempertahankan customer loyal, dan meningkatkan traffic pengunjung

\section{SARAN}

1. Secara bertahap Tangcity Mall dapat membuat konsep video promosi yang inovatif setiap tahunnya dengan ditambah visual effect dengan durasi video yang tidak terlalu lama agar lebih menarik bagi masyarakat dan Tangcity Mall selalu dapat memperbaharui informasi yang terkait mekanisme dan rewards dari event Smart Shopper Surprize setiap periodenya.

2. Disarankan kepada Tangcity Mall untuk dapat lebih mengimplementasikan video promosi ini melalui berbagai event yang diadakan oleh Tangcity Mall dan diinformasikan melalui media sosial seperti Instagram Tangcity Mall, sehingga masyarakat dapat dengan mudah memperoleh informasi seputar program event Smart Shopper Surprize sesuai dengan periode yang berjalan. 


\section{DAFTAR PUSTAKA}

[1] Noor, Any. 2009. Manajemen Event. Penerbit Alfabeta. Bandung

[2] Maulani, Giandari. Noviar Jalu Sasongko Dan Ardi Mulyana. 2016. Pengembangan Media Promosi Pariwisata Kota Tangerang Dalam Bentuk Video Digital Pada Dinas Porparekraf.Tangerang : Universitas Raharja. ICIT Journal. Vol. 2 No $2: 212$

[3] Handayani, Indri. Ade Setiadi dan Rizki Ramadani. 2019. Video Company Profile LIVE Kota Tangerang Dengan Teknik Editing Menggunakan Adobe Premiere Pro.Tangerang : STMIK Raharja. Jurnal Technomedia. ISSN : 2528 -6544. Vol. 3, No. $2: 133-145$

[4] Ismayani, Diah. 2018. Perancangan Video Iklan Promosi Profil Wisata Puncak Bila Riase' Kabupaten Sidrap.Makassar : Universitas Negeri Makassar. Jurnal Imajinasi. ISSN : 2550-102X. Vol. 2 No 1

[5] Prasetyo, Dwi dan Denny Indrayana Setyadi. 2017. Perancangan Film Pendek Bertema Wisata dengan Pendekatan Storytelling sebagai Media Promosi Pulau Bawean. Tangerang : Institut Teknologi Sepuluh Nopember. Jurnal Sains dan SeniITS. ISSN : 2337-3520. Vol. 6 No. 1

[6] Putra, Azwar Aditya dan Vella Carisa. 2019. Video Kabupaten Tangerang Pada Dinas Disporabudpar Pariwisata.Tangerang : STMIK Raharja. Jurnal CICES. ISSN : 23565209. Vol. 5, No.1 : 64-73.

[7] Yang Lai Fong, Dyuty Firoz dan Wan Idros Wan Sulaiman. 2017. The Impact of Tourism Advertisement Promotional Videos on Young Adults.Malaysia : Universiti Kebangsaan Malaysia. Journal of Social Sciences and Humanities. ISSN: 1823-884x. Vol.12 No.3

[8] Sunarya, Lusyani. Rindang Kusumaninggar dan Adrian Syahputra. 2017. Perancangan Media Promosi Video Profile Pada SMA Negeri 15 Kota Tangerang. Bali : STIKOM Bali. Jurnal Eksplora Informatika. ISSN : 2089-1814. Vol. 6, No. 2 : 108-111.

[9] Fatoni, Ahmad dan Nofi Puspitasari. 2016. Perancangan Simulasi Pengembangan Sistem Programming Penyaluran Dana Zakat di Badan Amil Zakat Kota Serang Berbasis Multimedia. Serang : Universitas Serang Raya. Jurnal PROSISKO. ISSN: 2406-7733. Vol.3, No.2 : 58.

[10] Sunarya, Lusyani. Putri Apryllia dan Siti Isnaini. 2016. Design Video Profile Based Multimedia Audio Visual and Broadcasting as a Media Promotion. Tangerang : Universitas Raharja. CCIT Journal. ISSN : 1978 -8282 Vol. 9 No.3 : 320-321

[11] Tama, Adi Kusuma Widya. Azwar Aditya Putra dan Muhamad Azis Fikri. 2018. Video Profile Jurusan Sistem Komputer Jenjang Strata Satu pada STMIK Raharja Tangerang. Tangerang : Universitas Raharja. CERITA Journal. ISSN : 2461-1417 Vol. 4 No.2 : 103 